Short Communication

\title{
Outbreak of common midwife toad virus in alpine newts (Mesotriton alpestris cyreni) and common midwife toads (Alytes obstetricans) in Northern Spain: A comparative pathological study of an emerging ranavirus
}

\author{
Ana Balseiro ${ }^{\mathrm{a}, *}$, Kevin P. Dalton ${ }^{\mathrm{b}}$, Ana del Cerro ${ }^{\mathrm{a}}$, Isabel Márquez ${ }^{\mathrm{a}}$, Francisco Parra ${ }^{\mathrm{b}}$, \\ José M. Prieto ${ }^{a}$, R. Casais ${ }^{\text {a }}$ \\ a SERIDA, Servicio Regional de Investigación y Desarrollo Agroalimentario, Laboratorio de Sanidad Animal, 33299 Jove, Gijón, Spain \\ ${ }^{\mathrm{b}}$ Departamento de Bioquímica y Biología Molecular, Instituto Universitario de Biotecnología de Asturias, Universidad de Oviedo, 33006 Oviedo, Spain
}

\section{A R T I C L E I N F O}

Article history:

Accepted 31 July 2009

\section{Keywords:}

Ranavirus

Common midwife toad virus

Alpine newt

Mesotriton alpestris cyreni

Pathology

Immunohistochemistry

\begin{abstract}
A B S T R A C T
This report describes the isolation and characterisation of the common midwife toad virus (CMTV) from juvenile alpine newts (Mesotriton alpestris cyreni) and common midwife toad (CMT) tadpoles (Alytes obstetricans) in the Picos de Europa National Park in Northern Spain in August 2008. A comparative pathological and immunohistochemical study was carried out using anti-CMTV polyclonal serum. In the kidneys, glomeruli had the most severe histological lesions in CMT tadpoles, while both glomeruli and renal tubular epithelial cells exhibited foci of necrosis in juvenile alpine newts. Viral antigens were detected by immunohistochemical labelling mainly in the kidneys of CMT tadpoles and in ganglia of juvenile alpine newts. This is the first report of ranavirus infection in the alpine newt, the second known species to be affected by CMTV in the past 2 years.
\end{abstract}

(c) 2009 Elsevier Ltd. All rights reserved.
In recent years, chytridiomycosis and ranavirus infections have caused outbreaks of high mortality in amphibians and appear to be linked to amphibian population declines (Daszak et al., 1999). The number of reported ranavirus outbreaks has increased greatly since the 1990s, with recurring epidemics occurring in native amphibian populations in the United Kingdom (Cunningham et al., 1996; Teacher et al., 2009).

The common midwife toad virus (CMTV) is a ranavirus originally isolated from common midwife toad (CMT) tadpoles (Alytes obstetricans) from the Picos de Europa National Park in Northern Spain in September 2007 (Balseiro et al., 2009). This was the first description of a ranavirus disease in Spain. No further cases of the disease were detected until August 2008, when high mortality was observed in CMT tadpoles and juvenile alpine newts (Mesotriton alpestris cyreni) in a pond approximately $1 \mathrm{~km}$ from the permanent water trough where the first outbreak occurred. In this study we report the isolation of CMTV from juvenile alpine newts, along with CMT tadpoles at the same location, and perform a comparative pathological and immunohistochemical study. No further cases of CMTV infection were detected in the permanent water trough, which had been disinfected after the outbreak in 2007.

Macroscopically, CMT tadpoles exhibited systemic haemorrhages. Juvenile alpine newts had haemorrhages on the ventral surface (Fig. 1), but not in internal organs. Systemic haemorrhages are

\footnotetext{
* Corresponding author. Tel.: +34 985 308470; fax: +34 985327811 .

E-mail address: abalseiro@serida.org (A. Balseiro).
}

common in ranavirus infections (Fox et al., 2006; Cunningham et al., 2008). However, in the United Kingdom, ranavirus infection can present with cutaneous ulceration but no internal gross lesions (Cunningham et al., 1996, 2008). Microscopic lesions in CMT tadpoles and juvenile alpine newts in the present outbreak were similar to those described for the systemic haemorrhagic form of ranavirus disease in CMT tadpoles previously (Balseiro et al., 2009).

Three whole CMT tadpoles and three juvenile alpine newts were fixed in $10 \%$ neutral buffered formalin immediately after death, dehydrated in graded ethanol solutions, embedded in paraffin wax, sectioned at $4 \mu \mathrm{m}$ thickness and stained with haematoxylin and eosin (H\&E). On histopathological examination, intracytoplasmic inclusion bodies (Fig. 2) were associated with small foci of necrosis in the skin, liver, kidney, pancreas and gastrointestinal tract. Pycnotic cell nuclei were also observed in these organs. Vesicles and focal thickening were observed in the epidermis in both species. In the kidneys, glomeruli were the structures most affected in CMT tadpoles, while both glomeruli and tubular epithelial cells exhibited foci of necrosis (Fig. 2C) in juvenile alpine newts. Another ranavirus, FV3, exhibits trophism for the kidney, specifically for the proximal renal tubular epithelium (Robert et al., 2005). Necrosis of neuroepithelial tissue, previously described in salamanders (Docherty et al., 2003), was not found in infected CMT tadpoles or juvenile alpine newts.

Samples of kidneys from CMT tadpoles and juvenile alpine newts were fixed in 2.5\% glutaraldehyde, embedded in resin and ultrathin sections were stained with uranyl acetate and lead citrate 


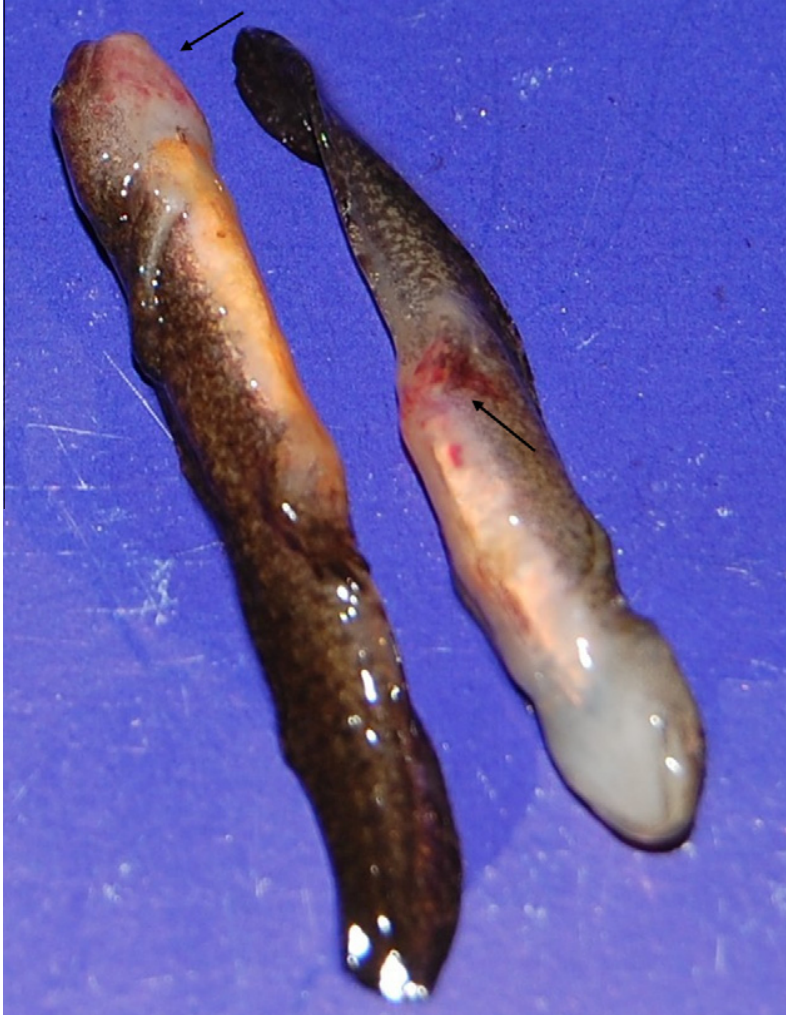

Fig. 1. Two juvenile alpine newts (Mesotriton alpestris cyreni), about $5 \mathrm{~cm}$ in length, infected with CMTV, showing skin haemorrhages on their ventral body surfaces (arrows).

for transmission electron microscopy (TEM) using a JEOL JEM-1010 microscope. Virions were detected in the kidneys of both CMT tadpoles and juvenile alpine newts examined by TEM (Fig. 3B and C).
Most virions appeared to be extracellular and were located in areas of necrosis found on histological examination. Virus particles appeared to be more abundant in CMT tadpoles than juvenile alpine newts.

Epithelioma papulosum cyprini (EPC) cells were inoculated with tissue homogenates of lung, liver, kidney and gastrointestinal tract from four diseased CMT tadpoles and four diseased juvenile alpine newts for virus isolation (Balseiro et al., 2009). Cytopathic effects were evident after incubation for 5 days at $15^{\circ} \mathrm{C}$. Virions were purified from EPC-infected cells (Balseiro et al., 2009) and negatively stained with $2 \%$ phosphotungstic acid ( $\mathrm{pH}$ 6.2). Electron microscopy demonstrated enveloped iridovirus-like virions approximately $160-180 \mathrm{~nm}$ in diameter with hexagonal nucleocapsid morphology (Fig. 3A).

DNA was extracted from tissue homogenates of diseased animals, using the illustra tissue and cells genomicPrep Mini Spin Kit (GE Healthcare) and amplified by PCR using as forward primer 5'-GACTTGGCCACTTATGAC-3' and reverse primer 5'-GTCTCTGGAGAAGAAGAA-3' within the FV3 major capsid protein (MCP) gene (Mao et al., 1997). The DNA products (530 nucleotides, including the primer sequences) were gel-purified using the TaKaRa RECOCHIP and sequenced using the ABI prism BigDye terminator v3.1 kit (Applied BioSystems) and the Applied BioSystems 3100 Genetic Analyser. The nucleotide sequences obtained for the viruses isolated from CMT tadpoles and juvenile adult newts in the August 2008 outbreak were identical to each other and to that of the CMTV isolated in September 2007 (GenBank FM213466; Balseiro et al., 2009). These results suggest that the viruses isolated from CMT tadpoles and juvenile alpine newts in the 2008 outbreak are most likely to be CMTV.

Immunohistochemistry was performed using the peroxidase anti-peroxidase method. Sections were incubated with specific rabbit anti-serum raised against purified virions of the 2007 isolate CMTV and diluted 1/1000 (Balseiro et al., 2009). In CMT tadpoles, the strongest staining on immunohistochemistry was observed in renal glomeruli (Fig. 2B). However, in juvenile alpine newts,

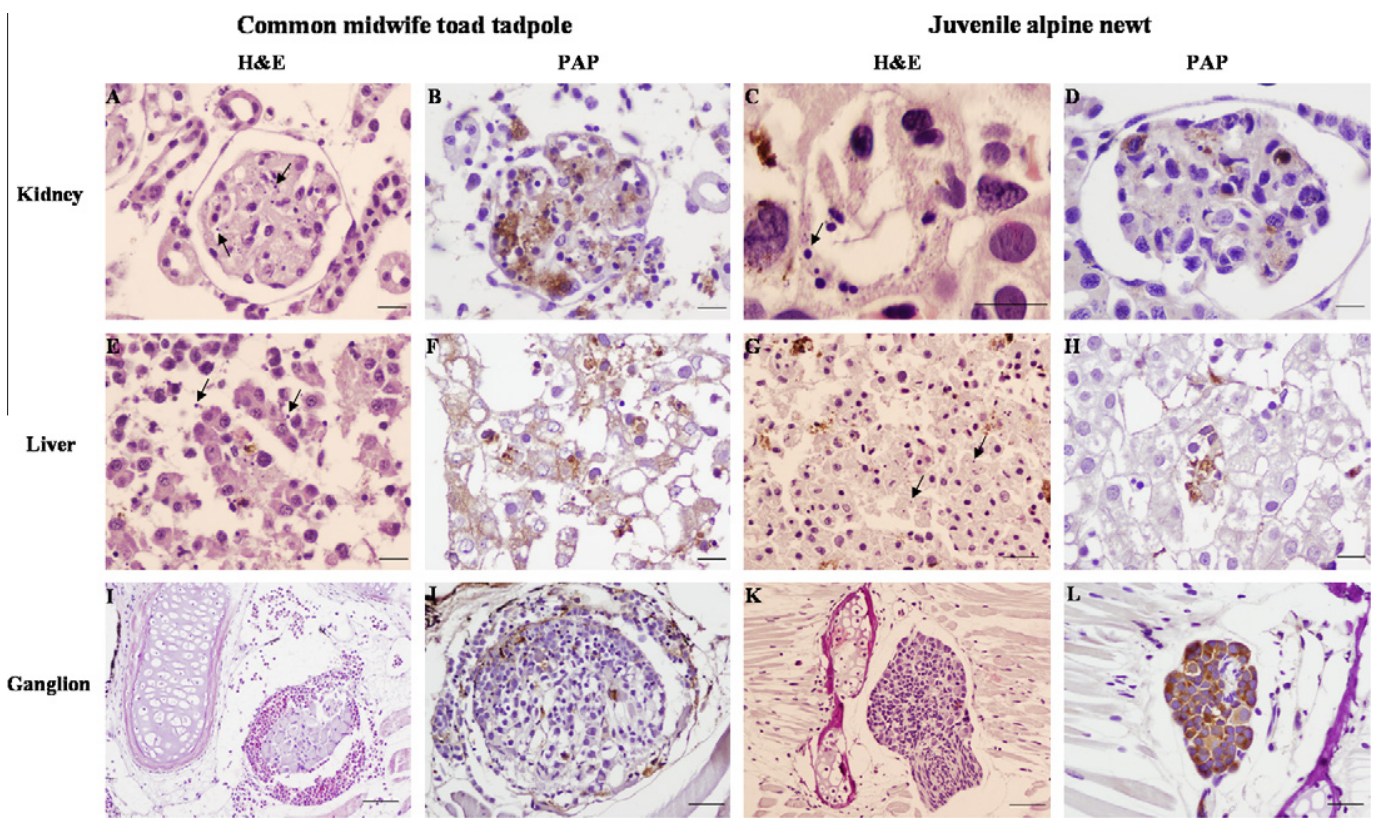

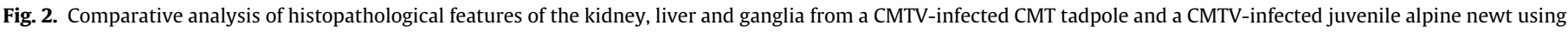

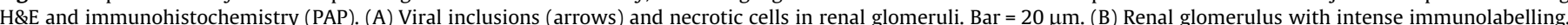

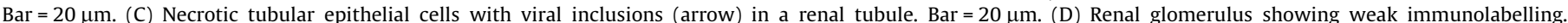

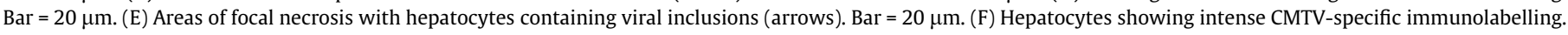

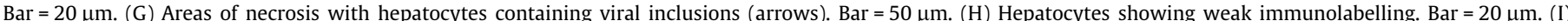

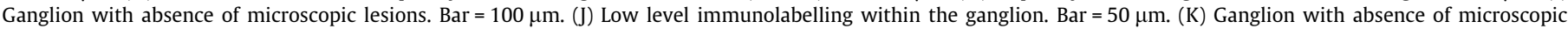

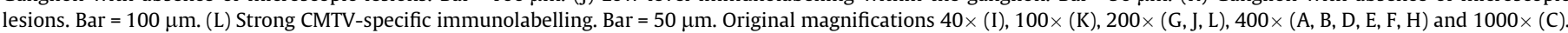


A

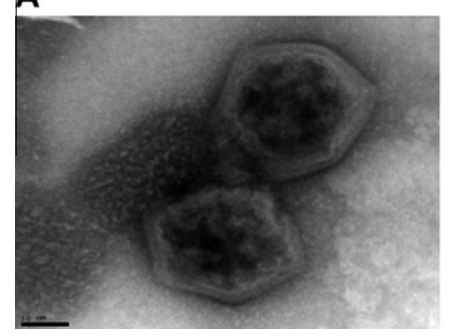

B

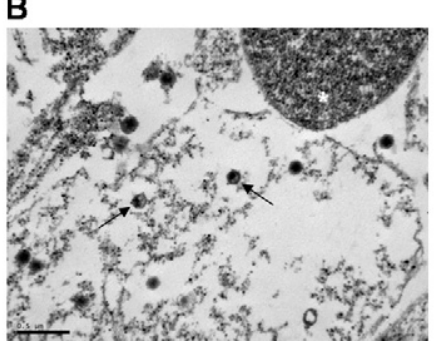

C

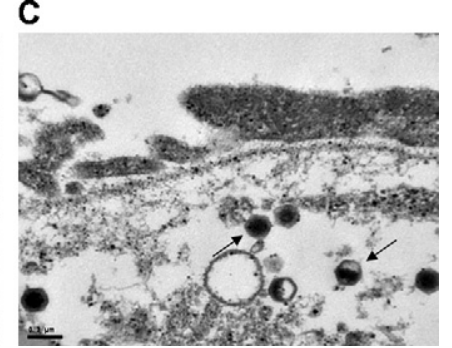

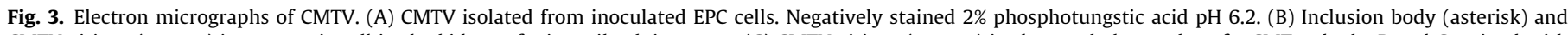

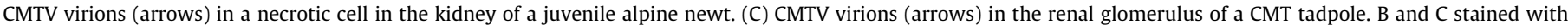
uranyl acetate and lead citrate. Scale bars $=50 \mathrm{~nm}$. Original magnifications $200,000 \times(A), 25,000 \times(B), 50,000 \times(C)$.

ganglia located in the muscle were most strongly immunolabelled (Fig. 2L), although necrosis or viral inclusions were not observed at these sites (Fig. 2K). In both species, there was focal immunolabelling of CMTV antigen in the epidermis and dermis. CMTV antigen was also detected in the intestinal mucosa and occasionally in endothelial cells in the submucosa. Antigen labelling within the pancreas was detected in the exocrine glandular cells.

This study shows that the alpine newt is susceptible to CMTV infection. Ranavirus transmission could be occurring between the CMT and alpine newts in the North of Spain. It is not known whether other amphibians, fish or reptiles are susceptible to CMTV infection, but other ranaviruses, such as FV3, can infect a variety of amphibian and fish species (Duffus et al., 2008). Subclinical infections with ranaviruses have been documented in free-ranging amphibians and clinical signs in late stage tadpoles sometimes resolve (Fox et al., 2006). Adult frogs may serve as reservoirs of the virus (Robert et al., 2005; Fox et al., 2006). In both outbreaks of CMTV in Spain, mortality was observed in larvae or juvenile amphibians, but not in adults. It is not known if CMTV has an intraspecific reservoir similar to Ambystoma tigrinum (Brunner et al., 2004).

This is the first report of a ranavirus infection in the alpine newt and the second species known to be infected with CMTV in the past 2 years. The alpine newt is considered to be vulnerable in Spain (Nores et al., 2007) and it is important to monitor CMTV in this species to prevent its extinction due to this infection.

\section{Conflict of interest statement}

None of the authors of this paper has a financial or personal relationship with other people or organisations that could inappropriately influence or bias the content of the paper.

\section{Acknowledgements}

The authors wish to thank the Veterinary Services of the Picos de Europa National Park, the Electron Microscopy Area of the University of León and P. Solano for helping with the processing of samples. A.B. is a recipient of a Contrato de Investigación para
Doctores from the Instituto Nacional de Investigación Agraria y Agroalimentaria (INIA) and R.C. is recipient of a Ramón y Cajal contract from the Spanish Ministerio de Educación y Ciencia co-financed by Fondo Social Europeo.

\section{References}

Balseiro, A., Dalton, K.P., Del Cerro, A., Márquez, I., Cunningham, A.A., Parra, F., Prieto, J.M., Casais, R., 2009. Pathology, isolation and molecular characterization of a ranavirus from the common midwife toad (Alytes obstetricans) on the Iberian Peninsula. Diseases of Aquatic Organisms 84, 95-104.

Brunner, J.L., Schock, D.M., Davidson, E.W., Collins, J.P., 2004. Intraspecific reservoirs: complex life history and the persistence of a lethal ranavirus. Ecology 85, 560-566.

Cunningham, A.A., Langton, T.E.S., Bennett, P.M.B., Lewin, J.F., Drury, S.E.N., Gough, R.E., Macgregor, S.K., 1996. Pathological and microbiological findings from incidents of unusual mortality of the common frog (Rana temporaria). Philosophical Transactions of the Royal Society of London: Biological Sciences 351, 1539-1557.

Cunningham, A.A., Tems, C.A., Russell, P.H., 2008. Immunohistochemical demonstration of ranavirus antigen in the tissues of infected frogs (Rana temporaria) with systemic haemorrhagic or cutaneous ulcerative disease. Journal of Comparative Pathology 138, 3-11.

Daszak, P., Berger, L., Cunningham, A.A., Hyatt, A.D., Green, D.E., Speare, R., 1999 Emerging infectious diseases and amphibian population declines. Emerging Infectious Diseases 5, 735-748.

Duffus, A.L.J., Pauli, B.D., Wozney, K., Brunetti, C.R., Berrill, M., 2008. Frog virus 3-like infections in aquatic amphibian communities. Journal of Wildlife Diseases 44 , $109-120$.

Docherty, D.E., Meteyer, C.U., Wang, J., Mao, J., Case, S.T., Chinchar, V.G., 2003 Diagnostic and molecular evaluation of three iridovirus-associated salamander mortality events. Journal of Wildlife Diseases 39, 556-566.

Fox, S.F., Greer, A.L., Torres-Cervantes, R., Collins, J.P., 2006. First case of ranavirusassociated morbidity and mortality in natural populations of the South American frog Atelognathus patagonicus. Diseases of Aquatic Organisms 72, 87-92.

Mao, J., Hedrick, R.P., Chinchar, V.G., 1997. Molecular characterization, sequence analysis, and taxonomic position of newly isolated fish iridoviruses. Virology 229, 212-220.

Nores, C., García Rovés, P., Segura, A., 2007. Anfibios. In: Nores, C., García Rovés, P. (Eds.), Libro Rojo de la Fauna del Principado de Asturias. Imprastur, Asturias, Spain, pp. 162-163.

Robert, J., Morales, H., Back, W., Cohen, N., Marr, S., Gantress, J., 2005. Adaptive immunity and histopathology in frog virus-3 infected Xenopus. Virology 332, 667-675.

Teacher, A.G.F., Garner, T.W.J., Nichols, R.A., 2009. Evidence for directional selection at a novel major histocompatibility class I marker in wild common frogs (Rana temporaria) exposed to a viral pathogen (ranavirus). Public Library of Science 4 , e4616. 